\title{
Toll-like receptor 4 monoclonal antibody attenuates lipopolysaccharide-induced acute lung injury in mice
}

\author{
ZHIJIE HE ${ }^{1}$, XIAOTONG CHEN ${ }^{1}$, SHOUPING WANG ${ }^{2}$ and ZIJUN ZOU ${ }^{1}$ \\ Departments of ${ }^{1}$ Critical Care Medicine and ${ }^{2}$ Anesthesiology, Sun Yat-sen Memorial Hospital, \\ University of Sun Yat-sen, Guangzhou, Guangdong 510120, P.R. China \\ Received January 15, 2014; Accepted May 9, 2014
}

DOI: $10.3892 /$ etm.2014.1805

\begin{abstract}
Toll-like receptor 4 (TLR4) has an important role in the recognition of lipopolysaccharide (LPS) and in the activation of the inflammatory cascade. In the present study, the effect of TLR4 monoclonal antibody (mAb) on LPS-induced acute lung injury (ALI) was investigated in mice. A total of 45 male $\mathrm{BALB} / \mathrm{c}$ mice were randomly divided into three groups, namely, the control (group C), sepsis (group S) and pretreatment groups (group P). Mice in group P were intraperitoneally treated with TLR4 mAb $1 \mathrm{~h}$ prior to the intraperitoneal administration of LPS. Following treatment with LPS for increasing times periods in groups $\mathrm{S}$ and $\mathrm{P}$, the mRNA expression level of TLR4 in the lung tissue and the expression of inflammatory factors in the serum were analyzed by quantitative polymerase chain reaction and enzyme-linked immunosorbent assays, respectively. The degree of pulmonary edema, expressed as (wet weight - dry weight)/wet weight, as well as the lung injury scores, observed using a light microscope, were also analyzed. The results demonstrated that intraperitoneal administration of LPS in mice increased the mRNA expression levels of TLR4, the secretion of inflammatory factors in the serum, the degree of pulmonary edema and the lung injury score in a time-dependent manner. However, pretreatment with TLR4 $\mathrm{mAb}$ effectively attenuated the increased mRNA expression of TLR4 and the overproduction of inflammatory factors to correct the pulmonary edema and the elevated lung injury score induced by LPS. Therefore, TLR4 plays a critical role in LPS-induced ALI, and the TLR4 mAb decreases the secretion of inflammatory factors and attenuates the degree of pulmonary edema, thereby protecting the lungs from LPS-induced ALI.
\end{abstract}

Correspondence to: Dr Zhijie He, Department of Critical Care Medicine, Sun Yat-sen Memorial Hospital, University of Sun Yat-sen, No. 107 West of Yanjiang Road, Guangzhou, Guangdong 510120, P.R. China

E-mail: zhijiehecn@163.com

Key words: Toll-like receptor 4 monoclonal antibody, acute lung injury, pulmonary edema, lung protection, rodents

\section{Introduction}

Sepsis is a complex clinical syndrome that is caused by a harmful host response to infection. Numerous advances have been made in antibiotic therapy and supportive care; however, sepsis remains a major cause of mortality in intensive care units. The lung is the most vulnerable organ during sepsis (1). During the development of sepsis, bacterial components, such as lipopolysaccharide (LPS), may activate an inflammatory cascade, which results in the release of inflammatory mediators. The overproduction of inflammatory mediators induces endothelial and epithelial injury, vascular leakage, edema and vasodilatation, subsequently causing the development of acute lung injury (ALI) and acute respiratory distress syndrome (ARDS) $(2,3)$. Previous studies have shown that inflammatory mediators have a key function in the pathogenesis of ALI/ARDS. ALI is characterized by a local inflammatory response, and Toll-like receptor 4 (TLR4) has an important function in the activation of innate immunity via recognizing LPS $(4,5)$. Based on the key role of inflammatory mediators in the pathogenesis of ALI, recent treatments have been aimed at modulating TLR4 signaling and alleviating nonspecific inflammatory reactions that may result in potential therapeutic advantages for ALI.

As an essential receptor for LPS signaling, TLR4 may trigger the activation of an extracellular signaling pathway and result in the upregulation of inflammatory mediators $(1,6)$. A previous study demonstrated that therapeutic antagonism of TLR4 signaling protects against ALI (7). To neutralize LPS signaling, the specific TLR4 monoclonal antibody (mAb) was used in the present study to evaluate the effect on an experimental model of ALI. It was hypothesized that suppressing TLR4-associated production of inflammatory mediators by pretreatment with TLR4 $\mathrm{mAb}$ may be a promising therapeutic strategy for the treatment of ALI.

\section{Materials and methods}

Animals. A total of 45 male BALB/c mice, weighing between 18 and $20 \mathrm{~g}$, were obtained from the Guangdong Province Medical Experiments Animal Center. Mice were provided with free access to water and standard rodent chow, and were housed in pathogen-free cages. The study was performed in accordance with the recommendations in the Guide for the 
Table I. Water content in the lung tissue of each group.

\begin{tabular}{lccc}
\hline Parameter & $6 \mathrm{~h}$ & $12 \mathrm{~h}$ & $24 \mathrm{~h}$ \\
\hline Group C (\%) & $72.47 \pm 2.89$ & $71.32 \pm 4.13$ & $71.20 \pm 3.11$ \\
Group S (\%) & $77.63 \pm 4.13$ & $84.29 \pm 4.69^{\mathrm{a}, \mathrm{c}}$ & $87.23 \pm 5.12^{\mathrm{a}, \mathrm{c}, \mathrm{d}}$ \\
Group P (\%) & $76.65 \pm 5.32$ & $78.35 \pm 3.61^{\mathrm{a}, \mathrm{b}}$ & $83.32 \pm 4.87^{\mathrm{a}, \mathrm{b}, \mathrm{d}, \mathrm{d}}$ \\
F-value & 2.09 & 13.32 & 17.55 \\
\hline
\end{tabular}

Results are expressed as the mean \pm standard deviation $(\mathrm{n}=5) .{ }^{\mathrm{a}} \mathrm{P}<0.05$, vs. group $\mathrm{C}$; ${ }^{\mathrm{b}} \mathrm{P}<0.05$, vs. group $\mathrm{S} ;{ }^{\mathrm{c}} \mathrm{P}<0.05$, vs. intra-group $6 \mathrm{~h}$; ${ }^{\mathrm{d}} \mathrm{P}<0.05$, vs. intra-group $12 \mathrm{~h}$. C, control; $\mathrm{S}$, sepsis; P, pretreatment. $\mathrm{n}$ is the number of mice used in each group.

Care and Use of Laboratory Animals of the National Institutes of Health. The animal use protocol was reviewed and approved by the Institutional Animal Care and Use Committee of Sun Yat-sen Memorial Hospital of the University of Sun Yat-sen (Guangzhou, China).

Experimental protocol. Mice were divided into three groups: Control (group C), sepsis (group S) and pretreatment (group P) groups. Mice in the $\mathrm{P}$ and $\mathrm{S}$ groups were intraperitoneally injected with $10 \mathrm{mg} / \mathrm{kg}$ LPS (Sigma-Aldrich, St. Louis, MO, USA) to establish an ALI model (8). Group P mice were also intraperitoneally injected with TLR4 mAb (5 $\mu \mathrm{g} / \mathrm{g}$; GeneTex, Irvine, CA, USA) $1 \mathrm{~h}$ prior to the injection of LPS. The mRNA expression levels of TLR4 in the lung tissue, as well as the serum expression levels of tumor necrosis factor (TNF)- $\alpha$ and interleukin (IL)-6, the water content of the lung and the pathomorphological changes in the lung, were detected after 6, 12 and $24 \mathrm{~h}$.

Analysis of inflammatory mediators in the serum. Mice were sacrificed via an intraperitoneal injection of $120 \mathrm{mg} / \mathrm{kg}$ pentobarbital, and blood samples were collected from the right atrium. The expression levels of TNF- $\alpha$ and IL- 6 in the serum were then determined using an enzyme-linked immunosorbent assay (ELISA; Biolegend, San Diego, CA, USA), in accordance with the manufacturer's instructions.

Lung histology. Following euthanasia, the lungs were excised from the mice by opening the chest via median sternotomy. The right inferior lobe was removed and fixed in $10 \%$ buffered formalin for $24 \mathrm{~h}$. Hematoxylin and eosin-stained sections were prepared using standard techniques as described by Szaka et al (9). The degree of microscopic injury was scored based on the following variables: Hemorrhage, edema, exudation, necrosis, congestion, neutrophil infiltration and atelectasis. The severity of injury was judged based on the following criteria (10): No injury, 0 ; injury to $25 \%$ of the field, 1 ; injury to $50 \%$ of the field, 2 ; injury to $75 \%$ of the field, 3; and diffuse injury, 4. The ultimate score was obtained by adding the aforementioned scores. A pathologist, who was blinded to the experimental protocol, provided a score for each variable based on the severity of injury $(11,12)$.

Water content of lung. Following euthanasia, the right middle lobe was excised from each mouse. The wet weight of the lung was measured using an electronic scale and then desiccated in an oven at $85^{\circ} \mathrm{C}$ for $48 \mathrm{~h}$ to determine the dry weight. The water content was obtained using the following equation: Water content $(\%)=($ wet weight - dry weight $) /$ wet weight $\mathrm{x} 100 \%$.

Expression of TLR4 mRNA in the lung tissue. The mRNA expression levels of TLR4 were analyzed by quantitative polymerase chain reaction. Total RNA was isolated from the lung tissue using TRIzol reagent (Invitrogen Life Technologies, Carlsbad, CA, USA) and subsequently reverse-transcribed into cDNA using Superscript II RNase H-Reverse Transcriptase (Invitrogen Life Technologies). The sequence-specific primers used were as follows: $\beta$-actin (sense), 5'-TACAGCTTCACCACCACAGC-3' and antisense, 5'-AAGGAAGGCTGGAAGAGAGC-3'; TLR4 sense, 5'-TGCAATGTGAGCATTGATGA-3' and antisense, 5'-TGACACCATTGAAGCTGAGG-3'.

Statistical analysis. All data are presented as the mean \pm standard deviation. GraphPad Prism 4.0 software (GraphPad Software, Inc., San Diego, CA, USA) was used for statistical analysis. Data were analyzed using one-way analysis of variance (ANOVA) by comparing the inter-group results and via two-way ANOVA by comparing the intra-group results. $\mathrm{P}<0.05$ was considered to indicate a statistically significant difference.

\section{Results}

Water content in the lung tissue. As shown in Table I, the changes in the water content in the lungs of the mice in groups $\mathrm{C}, \mathrm{S}$ and $\mathrm{P}$ were not statistically different at $6 \mathrm{~h}(\mathrm{P}>0.05)$. However, when the LPS treatment time was increased, the water content in the lung tissue increased by $\sim 13$ and $16 \%$ at 12 and $24 \mathrm{~h}$, respectively, as compared with group C. This result is in accordance with the changes observed in ALI. Pretreatment with TLR4 $\mathrm{mAb}$ prior to treatment with LPS was found to correct the LPS-induced increase in the water content of the lung tissue $(\mathrm{P}<0.05)$.

Expression of TNF- $\alpha$ in the serum. To evaluate the effect of TLR4 $\mathrm{mAb}$ on an LPS-induced inflammatory mediator, the expression of TNF- $\alpha$ in the serum was measured using ELISA. As shown in Table II, the expression of TNF- $\alpha$ in group $\mathrm{S}$ significantly increased by $230 \mathrm{pg} / \mathrm{ml}$ maximally at $6 \mathrm{~h}(\mathrm{P}<0.05)$ when compared with group $\mathrm{C}$. Compared with group S, pretreatment with TLR4 mAb prior to LPS treatment 
Table II. Serum expression levels of TNF- $\alpha$ in each group.

\begin{tabular}{lccc}
\hline Parameter & $6 \mathrm{~h}$ & $12 \mathrm{~h}$ & $24 \mathrm{~h}$ \\
\hline Group C (pg/ml) & $29.45 \pm 5.25$ & $33.13 \pm 3.88$ & $34.08 \pm 4.12$ \\
Group S (pg/ml) & $259.12 \pm 19.81^{\mathrm{a}}$ & $186.21 \pm 13.75^{\mathrm{a}, \mathrm{c}}$ & $115.89 \pm 17.91^{\mathrm{a}, \mathrm{c}, \mathrm{d}}$ \\
Group P $(\mathrm{pg} / \mathrm{ml})$ & $156.85 \pm 14.11^{\mathrm{a}, \mathrm{b}}$ & $112.43 \pm 14.33^{\mathrm{a}, \mathrm{b}, \mathrm{c}}$ & $81.45 \pm 10.58^{\mathrm{a}, \mathrm{b}, \mathrm{c}, \mathrm{d}}$ \\
F-value & 324.96 & 214.53 & 56.21 \\
\hline
\end{tabular}

Results are expressed as the mean \pm standard deviation $(\mathrm{n}=5)$. ${ }^{\mathrm{a}} \mathrm{P}<0.05$,vs. group $\mathrm{C}$; ${ }^{\mathrm{b}} \mathrm{P}<0.05$, vs. group $\mathrm{S}$; ${ }^{\mathrm{c}} \mathrm{P}<0.05$, vs. intra-group $6 \mathrm{~h}$; ${ }^{\mathrm{d}} \mathrm{P}<0.05$, vs. intra-group $12 \mathrm{~h}$. TNF, tumor necrosis factor; $\mathrm{C}$, control; $\mathrm{S}$, sepsis; $\mathrm{P}$, pretreatment. $\mathrm{n}$ is the number of mice used in each group.

Table III. Serum expression levels of IL-6 in each group.

\begin{tabular}{lccc}
\hline Parameter & $6 \mathrm{~h}$ & $12 \mathrm{~h}$ & $24 \mathrm{~h}$ \\
\hline Group C (pg/ml) & $84.83 \pm 5.74$ & $86.52 \pm 7.37$ & $84.96 \pm 10.06$ \\
Group S (pg/ml) & $235.75 \pm 32.26^{\mathrm{a}}$ & $300.64 \pm 13.65^{\mathrm{a}, \mathrm{c}}$ & $394.58 \pm 13.55^{\mathrm{a}, \mathrm{c}, \mathrm{d}}$ \\
Group P $(\mathrm{pg} / \mathrm{ml})$ & $157.93 \pm 18.41^{\mathrm{a}, \mathrm{b}}$ & $204.58 \pm 15.40^{\mathrm{a}, \mathrm{b}, \mathrm{c}}$ & $308.59 \pm 14.11^{\mathrm{a}, \mathrm{b}, \mathrm{c}, \mathrm{d}}$ \\
F-value & 60.45 & 360.78 & 791.18
\end{tabular}

Results are expressed as the mean \pm standard deviation $(n=5)$. ${ }^{\mathrm{a}} \mathrm{P}<0.05$, vs. group $\mathrm{C}$; ${ }^{\mathrm{b}} \mathrm{P}<0.05$, vs. group $\mathrm{S} ;{ }^{\mathrm{c}} \mathrm{P}<0.05$, vs. intra-group $6 \mathrm{~h}$; ${ }^{\mathrm{d}} \mathrm{P}<0.05$, vs. intra-group $12 \mathrm{~h}$. IL, interleukin; C, control; S, sepsis; P, pretreatment. $\mathrm{n}$ is the number of mice used in each group.

Table IV. mRNA expression levels of TLR4/ $\beta$-actin in each group.

\begin{tabular}{lccc}
\hline Parameter & $6 \mathrm{~h}$ & $12 \mathrm{~h}$ & $24 \mathrm{~h}$ \\
\hline Group C (\%) & $0.304 \pm 0.031$ & $0.315 \pm 0.022$ & $0.309 \pm 0.025$ \\
Group S (\%) & $1.697 \pm 0.090^{\mathrm{a}}$ & $1.280 \pm 0.083^{\mathrm{a}, \mathrm{c}}$ & $0.913 \pm 0.093^{\mathrm{a}, \mathrm{c}, \mathrm{d}}$ \\
Group P (\%) & $1.201 \pm 0.053^{\mathrm{a}, \mathrm{b}}$ & $0.921 \pm 0.049^{\mathrm{a}, \mathrm{b}, \mathrm{c}}$ & $0.404 \pm 0.051^{\mathrm{a}, \mathrm{b}, \mathrm{c}, \mathrm{d}}$ \\
F-value & 70.21 & 58.35 & 36.48 \\
\hline
\end{tabular}

Results are expressed as the mean \pm standard deviation ( $\mathrm{n}=5$ ). ${ }^{\mathrm{a}} \mathrm{P}<0.05$, vs. group $\mathrm{C}$; ${ }^{\mathrm{b}} \mathrm{P}<0.05$, vs. group $\mathrm{S} ;{ }^{\mathrm{c}} \mathrm{P}<0.05$, vs. intra-group $6 \mathrm{~h}$; ${ }^{\mathrm{d}} \mathrm{P}<0.05$, vs. intra-group $12 \mathrm{~h}$. TLR, Toll-like receptor; C, control; S, sepsis; P, pretreatment.

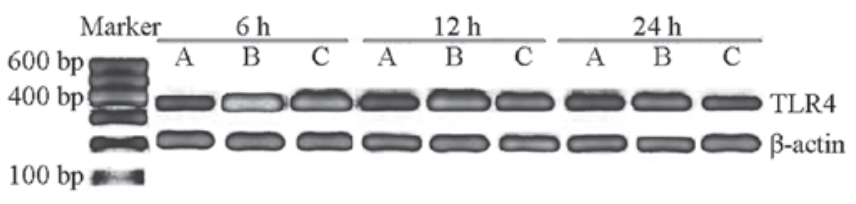

Figure 1. Product electropherogram of TLR4 mRNA, as determined by quantitative polymerase chain reaction. A, group $\mathrm{C}$; B, group $\mathrm{S}$; C, group P; TLR, Toll-like receptor; C, control; S, sepsis; P, pretreatment.

reduced the expression of TNF- $\alpha$ induced by LPS maximally by $100 \mathrm{pg} / \mathrm{ml}$ at $6 \mathrm{~h}(\mathrm{P}<0.05)$.

Expression of IL- 6 in the serum. Changes in the serum expression levels of IL-6 were also investigated, and the results were similar to those observed with TNF- $\alpha$. As shown in Table III, the expression levels of IL-6 in group S significantly increased by $310 \mathrm{pg} / \mathrm{ml}$ maximally at $24 \mathrm{~h}(\mathrm{P}<0.05)$ when compared with group $\mathrm{C}$, and pretreatment with TLR4 $\mathrm{mAb}$ also effectively inhibited the increase in TNF- $\alpha$ expression induced by LPS
$(\mathrm{P}<0.05)$. These results indicated that pretreatment with TLR4 $\mathrm{mAb}$ may correct the expression of LPS-induced inflammatory mediators.

Expression of TLR4 mRNA in the lung tissue. The mRNA expression level of TLR4 in group C was $0.304 \pm 0.03$. The mRNA expression level of TLR4 in group S significantly increased compared with that in group $\mathrm{C}(\mathrm{P}<0.05)$, and the peak value was observed at $6 \mathrm{~h}(1.697 \pm 0.090)$, which then gradually decreased after 12 and $24 \mathrm{~h}(1.280 \pm 0.083$ and $0.913 \pm 0.093$, respectively). However, the expression levels of TLR4 mRNA at 6,12 and $24 \mathrm{~h}$ in group $\mathrm{P}$ were $1.201 \pm 0.053,0.921 \pm 0.049$ and $0.404 \pm 0.051$, respectively, thus, were significantly decreased compared with group $\mathrm{S}(\mathrm{P}<0.05$; Table IV, Fig. 1). These observations indicated that TLR4 mAb may decrease the mRNA expression of TLR4 in the lung tissue of sepsis mice.

Pathological examination of the lung tissue using light microscopy. The pulmonary organizational structure of 
A

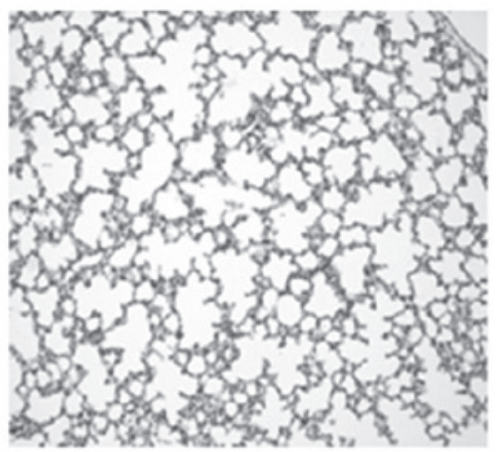

B

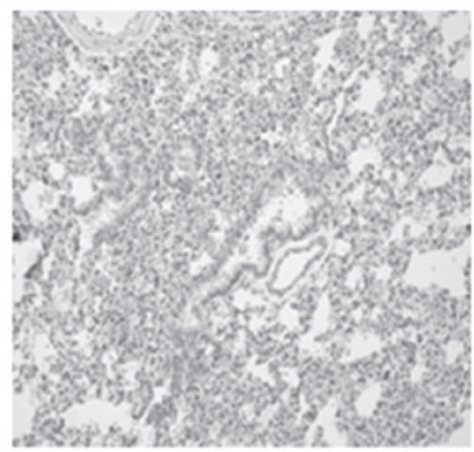

C

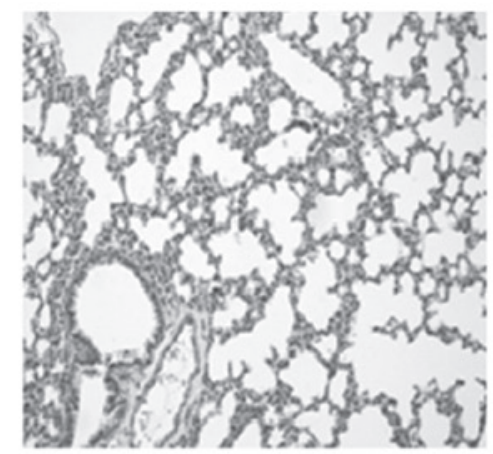

Figure 2. Changes in the histology and lung injury scores after $24 \mathrm{~h}$ in groups (A) C (lung injury score, 1), (B) S (lung injury score, 10) and (C) P (lung injury score, 4). Hematoxylin and eosin staining; magnification, x200. C, control; S, sepsis; P, pretreatment.

A

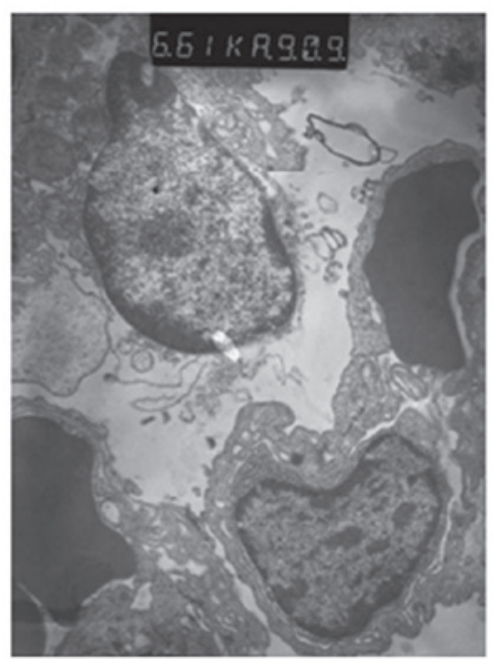

B

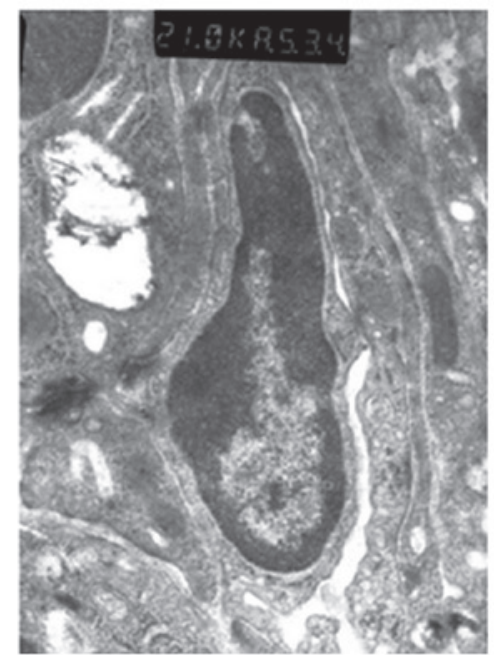

C

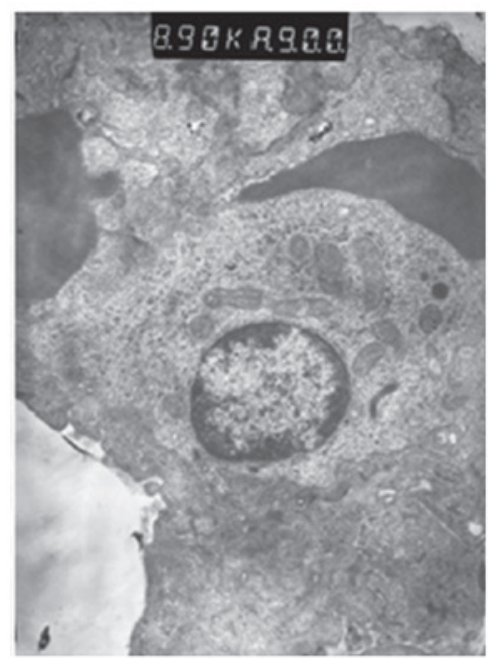

Figure 3. Ultrastructural changes of the lung tissue observed with electron microscopy after 12 h in groups (A) C, (B) S and (C) P. C, control; S, sepsis; P, pretreatment.

group $\mathrm{C}$ was normal. However, in group $\mathrm{S}$ at 6 and $12 \mathrm{~h}$, the dilation of the alveolus was not uniform since a number of the alveoli had collapsed. Incrassation of the alveoli septum, neutrophil infiltration and enlargement and congestion of the capillaries were also observed. The extent of the pathological changes was aggravated with increasing duration. In group $\mathrm{S}$ at $24 \mathrm{~h}$, in addition to the aforementioned pathological changes, airway trauma, lung edema and local lung hemorrhage were observed. The pathological changes in group P were significantly improved compared with those in group S (Fig. 2).

Ultrastructural changes of the lung tissue observed using electron microscopy. In group $\mathrm{C}$, the structure of the lung tissue and alveolar were normal and clear, and edema and inflammatory changes were observed. However, ultrastructural injury in the lung tissue was observed in group S. In addition, alveolar epithelial cell vacuolization and organelle swelling, dissolution and necrosis were observed. The nuclei of the cells were twisted, and sections of the chromatin were dissolved and had migrated to the edge of the cells. Alveolar wall thickening and capillary expansion, as well as pulmonary microvascular basement membrane thickening, were also observed. Over time, rupture with widened alveolar septa and pulmonary interstitial edema were observed, along with the infiltration of the alveolar space by numerous red blood cells and neutrophil granulocytes. The ultrastructural injury in group $\mathrm{P}$ was milder compared with group $\mathrm{S}$, in which pulmonary interstitial edema was not observed and cell infiltration was reduced (Fig. 3).

\section{Discussion}

TLRs were identified in the late 1990's as primary sensors of microbial infection, and their identification led to significant advances (13), including that TLRs were broadly involved in transducing sensory information in bacteria and TLR4 activated $\mathrm{NF}-\kappa \mathrm{B}$ triggers the production of several inflammatory cytokines. Currently, 12 members of the TLR family have been identified in mammalian cells (14). Among these, TLR4 detects the presence of gram-negative bacteria through the recognition of the lipid A moiety of LPS $(15,16)$. TLR4 is a type I integral membrane glycoprotein with a cytoplasmic signaling domain that is homologous to the signaling domain of the IL-1 receptor (IL-1R), known as the Toll/IL-1R homology (TIR) domain (17). Following ligand binding, TLR4 recruits the TIR-domain-containing adaptor molecules to the TIR domain. Myeloid differentiation factor 88 (MyD88) is an important adaptor molecule. Upon 
stimulation, MyD88 associates with the cytoplasmic domain of TLR4 and subsequently recruits IL-1R-associated kinase 1 (IRAK-1) and IRAK-4 (18-20), which mediate the activation of the transcriptional factor, nuclear factor (NF) $\kappa \mathrm{B}$, leading to the induction of inflammatory mediators. The initiation of the innate immune response through TLR4 triggers an inflammatory cascade that is the primary cause of harmful conditions, including ALI. Therefore, to suppress the inflammatory cascade effectively, we hypothesized that the inhibition of a point upstream of the TLR4 signaling pathway may be a better approach than inhibiting each mediator. Abraham (19) used a TNF- $\alpha$ mAb to treat septic shock, while Fisher (20) used an IL-1R antagonist in the treatment of patients with sepsis syndrome; however, the results were not satisfactory.

Previous studies have shown that the therapeutic antagonism of TLR4 signaling provides protection against ALI. Recently, Shirey et al (7) found that Eritoran (E5564), an extremely potent TLR4 antagonist, exhibits a highly protective effect when administered therapeutically to mice with influenza-induced ALI (7). In addition, it has previously been found that TLR4 mAb may function as a TLR4 antagonist and reduce the expression of IL-1 $\beta$ in LPS-stimulated decidual cells $(21,22)$. Furthermore, a previous study demonstrated that TLR4 $\mathrm{mAb}$ reduces LPS-induced cytokine production by inhibiting the NF- $\mathrm{BB}$ pathway in cells (23). ALI is characterized by a local inflammatory response, and the potential efficacy of TLR4 mAb to treat ALI is based on the hypothesis that TLR4 mAb suppresses the TLR4-associated inflammatory cascade of ALI. In the present study, TLR4 mAb was shown to exhibit a protective effect on LPS-induced ALI in mice. The expression levels of TNF- $\alpha$ and IL- 6 decreased, whilst lung histology and edema were markedly improved. However, the underlying mechanisms require further investigation.

In the present study, significantly increased serum levels of TNF- $\alpha$ and IL-6 were observed in group $S$ when compared with those in group $\mathrm{C}$, indicating that TNF- $\alpha$ and IL-6 have an important role in LPS-induced ALI. TNF- $\alpha$ is derived from activated macrophages and functions via specific cell membrane-bound receptors. Injecting TNF- $\alpha$ into experimental animals causes a syndrome similar to septic shock $(1,24,25)$. TNF- $\alpha$ is released during the first 30-90 min following exposure to LPS, which in turn activates a secondary level of the inflammatory cascade, including cytokines, lipid mediators and reactive oxygen species (1). IL-6 is produced by a wide range of cells, including macrophages and endothelial cells, in response to stimulation by factors, such as endotoxins and TNF- $\alpha$ (26-28). IL-6 is an important factor that amplifies the inflammatory reaction and stimulates the synthesis of acute phase protein $(29,30)$ Circulating levels of IL-6 are excellent predictors of the severity of ALI/ARDS of various etiologies (31). In the present study, significantly decreased levels of TNF- $\alpha$ and IL- 6 were observed in group $\mathrm{P}$ when compared with those in group $\mathrm{S}$. The inhibition of TLR4 signaling by TLR4 mAb resulted in the suppression of TNF- $\alpha$ and IL-6, which resulted in low-level lung edema and injury. TLR4 signaling is a critical activator of immune defense during infection, and the effective termination of TLR signaling is essential to prevent detrimental systemic effects, including septic shock (32). Therefore, the signaling mecha- nism of TLR4 mAb, the regulation of TLR4 expression on the cell surface and the transcriptional induction of negative regulators, including IL-1R-associated kinase and suppressor of cytokine signaling 1, requires further investigation (33).

In conclusion, TLR4 plays a critical role in LPS induced-ALI. TLR4 $\mathrm{mAb}$ reduces the secretion of inflammatory factors and attenuates the degree of pulmonary edema, thus, exhibits protective effects against LPS-induced ALI.

\section{Acknowledgements}

This study was supported by grants from the Natural Science Foundation of Guangdong Province (No S2013010014805) and Educational Commission of Guangdong Province (No. 2012B091100456).

\section{References}

1. Cohen J: The immunopathogenesis of sepsis. Nature 420: 885-891, 2002.

2. Ware LB and Matthay MA: The acute respiratory distress syndrome. N Engl J Med 342: 1334-1349, 2000.

3. Densmore JC, Signorino PR, Ou J, et al: Endothelium-derived microparticles induce endothelial dysfunction and acute lung injury. Shock 26: 464-471, 2006.

4. Cribbs SK, Matthay MA and Martin GS: Stem cells in sepsis and acute lung injury. Crit Care Med 38: 2379-2385, 2010.

5. Imai Y, Kuba K, Neely GG, et al: Identification of oxidative stress and Toll-like receptor 4 signaling as a key pathway of acute lung injury. Cell 133: 235-249, 2008.

6. Xu Y, Jagannath C, Liu XD, Sharafkhaneh A, Kolodziejska KE and Eissa NT: Toll-like receptor 4 is a sensor for autophagy associated with innate immunity. Immunity 27: 135-144, 2007.

7. Shirey KA, Lai W, Scott AJ, et al: The TLR4 antagonist Eritoran protects mice from lethal influenza infection. Nature 497: 498-502, 2013.

8. Tong Q, Zheng L, Kang Q, Dodd-O J, Langer J, Li B, Wang D and Li D: Upregulation of hypoxia-induced mitogenic factor in bacterial lipopolysaccharide-induced acute lung injury. FEBS Lett 580: 2207-2215, 2006.

9. Szarka RJ, Wang N, Gordon L, Nation PN and Smith RH: A murine model of pulmonary damage induced by lipopolysaccharide via intranasal instillation. J Immunol Methods 202: 49-57, 1997.

10. Mrozek JD, Smith KM, Bing DR, Meyers PA, Simonton SC, Connett JE and Mammel MC: Exogenous surfactant and partial liquid ventilation: physiologic and pathologic effects. Am J Respir Crit Care Med 156: 1058-1065, 1997.

11. Rotta AT and Steinhorn DM: Partial liquid ventilation reduces pulmonary neutrophil accumulation in an experimental model of systemic endotoxemia and acute lung injury. Crit Care Med 26: 1707-1715, 1998.

12. Nahum A, Hoyt J, Schmitz L, Moody J, Shapiro R and Marini JJ: Effect of mechanical ventilation strategy on dissemination of intratracheally instilled Escherichia coli in dogs. Crit Care Med 25: 1733-1743, 1997.

13. Rock FL, Hardiman G, Timans JC, Kastelein RA and Bazan JF: A family of human receptors structurally related to Drosophila Toll. Proc Natl Acad Sci USA 95: 588-593, 1998.

14. Akira S, Uematsu S and Takeuchi O: Pathogen recognition and innate immunity. Cell 124: 783-801, 2006.

15. Kumar H, Kawai T and Akira S: Pathogen recognition by the innate immune system. Int Rev Immunol 30: 16-34, 2011.

16. Huang S, Miao R, Zhou Z, et al: MCPIP1 negatively regulates Toll-like receptor 4 signaling and protects mice from LPS-induced septic shock. Cell Signal 25: 1228-1234, 2013.

17. Jenkins KA and Mansell A: TIR-containing adaptors in Toll-like receptor signalling. Cytokine 49: 237-244, 2010.

18. López-Bojórquez LN, Dehesa AZ and Reyes-Terán G: Molecular mechanisms involved in the pathogenesis of septic shock. Arch Med Res 35: 465-479, 2004.

19. Abraham E, Anzueto A, Gutierrez G, et al: Double-blind randomised controlled trial of monoclonal antibody to human tumour necrosis factor in treatment of septic shock. NORASEPT II Study Group. Lancet 351: 929-933, 1998. 
20. Fisher CJ Jr, Dhainaut JF, Opal SM, et al: Recombinant human interleukin 1 receptor antagonist in the treatment of patients with sepsis syndrome. Results from a randomized, double-blind, placebo-controlled trial. Phase III rhIL-1ra Sepsis Syndrome Study Group. JAMA 271: 1836-1843, 1994.

21. O'Neill LA and Bowie AG: The family of five: TIR-domain-containing adaptors in Toll-like receptor signalling. Nat Rev Immunol 7: 353-364, 2007.

22. Li Y, Zhong S and Yao R: Influence of LPS and Toll-like receptor 4 antagonist on progesterone receptor, interleukin-1 $\beta$, and cyclooxygenase-2 in decidual cells. Zhong Nan Da Xue Xue Bao Yi Xue Ban 38: 162-168, 2013 (In Chinese).

23. Tsukamoto H, Fukudome K, Takao S, Tsuneyoshi N, Ihara H, Ikeda Y and Kimoto M: Multiple potential regulatory sites of TLR 4 activation induced by LPS as revealed by novel inhibitory human TLR4 mAbs. Int Immunol 24: 495-506, 2012.

24. Norman JG, Fink GW and Franz MG: Acute pancreatitis induces intrapancreatic tumor necrosis factor gene expression. Arch Surg 130: 966-970, 1995.

25. Putensen $\mathrm{C}$ and Wrigge $\mathrm{H}$ : Ventilator-associated systemic inflammation in acute lung injury. Intensive Care Med 26: 1411-1413, 2000.

26. Bhatia M, Brady M, Shokuhi S, Christmas S, Neoptolemos JP and Slavin J: Inflammatory mediators in acute pancreatitis. J Pathol 190: 117-125, 2000.
27. Bhatia M, Neoptolemos JP and Slavin J: Inflammatory mediators as therapeutic targets in acute pancreatitis. Curr Opin Investig Drugs 2: 496-501, 2001

28. Bhatia M: Novel therapeutic targets for acute pancreatitis and associated multiple organ dysfunction syndrome. Curr Drug Targets Inflamm Allergy 1: 343-351, 2002.

29. Geiger T, Andus T, Klapproth J, Hirano T, Kishimoto T and Heinrich PC: Induction of rat acute-phase proteins by interleukin 6 in vivo. Eur J Immunol 18: 717-721, 1988.

30. Castell JV, Gómez-Lechón MJ, David M, et al: Interleukin-6 is the major regulator of acute phase protein synthesis in adult human hepatocytes. FEBS Lett 242: 237-239, 1989.

31. Remick DG, Bolgos GR, Siddiqui J, Shin J and Nemzek JA: Six at six: interleukin- 6 measured $6 \mathrm{~h}$ after the initiation of sepsis predicts mortality over 3 days. Shock 17: 463-467, 2002.

32. Szatmary Z: Molecular biology of Toll-like receptors. Gen Physiol Biophys 31: 357-366, 2012.

33. Liew FY, Xu D, Brint EK and O'Neill LA: Negative regulation of Toll-like receptor-mediated immune responses. Nat Rev Immunol 5: 446-458, 2005 